\title{
Corrigendum: Dry-spinning of cellulose nanocrystal/polylactic acid composite fibers
}

\section{Caitlyn M. Clarkson MSC}

Graduate student, School of Materials Engineering, Purdue University, West Lafayette, IN, USA (Orcid:0000-0001-9689-0842)
Jeffrey P. Youngblood PhD

Associate Professor, School of Materials Engineering, Purdue University, West Lafayette, IN, USA (corresponding author: jpyoungb@purdue.edu) (Orcid:0000-0002-8720-8642)

The authors regret that the following authors were omitted from the author list in this paper when it was published in Green Materials online Ahead of Print on 29 January 2018 (https:// doi.org/10.1680/jgrma.17.00027)

\section{Greg Schueneman}

Supervisory Research Materials Engineer, The Forest Products Laboratory, U.S. Forest Service, Madison, WI USA

\section{James Snyder}

Research Chemist, U.S. Army Research Laboratory, Aberdeen Proving Ground, MD, USA

The authorship list should be Clarkson, Schueneman, Snyder and Youngblood. 